\title{
A IMPORTÂNCIA DAS INCUBADORAS DE EMPRESAS PARA O DESENVOLVIMENTO ECONÔMICO SUSTENTÁVEL E REDUÇÃO DAS DISPARIDADES INTER-REGIONAIS: O CASO DA INCUBADORA DE EMPRESAS DO IFCE
}

\author{
AleXANDre COSTA Freitas ${ }^{1}$, \\ LAercio de Matos Ferreira ${ }^{1}$, MARia do Socorro Ribeiro Silva ${ }^{1}$ \\ ${ }^{1}$ Instituto Federal de Educação, Ciência e Tecnologia do Ceará, campus de Fortaleza. \\ <laerciomatosf@gmail.com>, <socorroribeiro1301@gmail.com>, <alexandre.cf@ hotmail.com.br>
}

DOI: 10.21439/conexoes.v10i3.872

\begin{abstract}
Resumo. O presente trabalho tem como objetivo analisar o papel que as incubadoras de empresas exercem como ferramentas de estímulo e consolidação do empreendedorismo em uma região, e em especial o fortalecimento das conexões entre as comunidades acadêmica e empresarial. A partir de um estudo de caso desenvolvido na Incubadora de Empresas do Instituto Federal de Educação, Ciência e Tecnologia do Ceará - IFCE, que se caracteriza pela complementação pedagógica das atividades desenvolvidas pelo Instituto Federal de Educação, Ciência e Tecnologia do Estado do Ceará, procurou-se estabelecer relações entre as incubadoras de empresas e o fenômeno crescente do empreendedorismo como fator de desenvolvimento e redução das desigualdades inter-regionais. O estudo confirmou a hipótese que o norteou, de que a ação de complementação pedagógica de uma incubadora eleva as possibilidades de êxito dos empreendimentos que abriga, e suscitou o aperfeiçoamento e replicação do modelo adotado pela Incubadora do IFCE.
\end{abstract}

Palavras-chaves: empreendedorismo; desenvolvimento; inovação; incubação.

\begin{abstract}
The present work aims to analyze the role of business incubators like tools of encouragement and consolidation of entrepreneurship in a region, specially strengthening the connections between academic and entrepreneur communities. From a case study in the Business Incubator of the Federal Institute of Education, Science and Technology of Ceara - IFCE, the study sought to establish a relationship between incubators companies and the growing phenomenon of entrepreneurship like a requirement for development and reduction of inter-regional disparities. The study confirmed its main hypothesis, that the action of pedagogic complementation in a Incubator increases the possibility of success of the entrepreneurship that the Incubator supports, and aroused the improvement and replication of the model adopted by the Incubator of IFCE.
\end{abstract}

Keywords: entrepreneurship, innovation, business incubator, incubation.

\section{INTRODUÇÃO}

O século XX é considerado por muitos como um período marcado por profundas transformações, chegando a ser considerado como o limiar de uma nova era, em que a virtualidade e a realidade estarão estritamente ligadas. O novo cenário mundial é por isso caracterizado por freqüentes e intensas mutações, provocadas por novos produtos, serviços, estruturas organizacionais e mercadológicas, que revolucionam o estilo de vida das pessoas, influenciando nos costumes e na cultura de diferentes civilizações. Por trás destas inovações, despontaram pessoas ou grupo de pessoas com características especiais e com visão de futuro que foram decisivos nessa revolução e escreveram seus nomes na história da humanidade. Essas pessoas ajudaram a construir um movimento que vem crescendo nos últimos anos em nível mundial e inspiram pessoas comuns a desenvolverem competências similares, para transformarem projetos em negócios inovadores. 
A IMPORTÂNCIA DAS INCUBADORAS DE EMPRESAS PARA O DESENVOLVIMENTO ECONÔMICO SUSTENTÁVEL E REDUÇÃO DAS DISPARIDADES INTER-REGIONAIS: O CASO DA INCUBADORA DE EMPRESAS DO IFCE

A estreita relação entre inovação e empreendedorismo deve-se principalmente ao economista austríaco Joseph Alois Schumpeter. O conceito, antes considerado uma qualidade inata de alguns seres humanos, passou, com os chamados "neoschumpeterianos", a contemplar qualquer indivíduo que busque capacitações para desenvolver projetos empreendedores. O empreendedor é visto hoje como alguém que se atualiza constantemente, para que sua disposição a riscos tenha um suporte suficiente para que sua atuação atinja os objetivos almejados.

O empreendedor, no entanto, não está sozinho na superação de seus obstáculos. Há organismos de suporte em várias etapas do processo, cujo conjunto integrado se convencionou chamar de Sistema de Inovação, com o objetivo maior de gerar uma ambiência favorável à sustentabilidade competitiva de projetos inovadores. A ação empreendedora sempre envolve riscos, que serão maiores se o ambiente apresentar turbulências econômicas. Além disso, processos com maiores níveis de agregação tecnológica apresentarão maiores riscos, mas em compensação, maiores expectativas de retorno. Devem ser por isso, alicerçados por ambientes dotados de maiores competências técnicas, científicas e mercadológicas.

As incubadoras de empresas, organizações sem fins lucrativos, normalmente vinculada a uma universidade ou a um órgão de ensino, configuram-se ambiências destinadas a amparar o desenvolvimento de empresas iniciantes por meio de um rol de suportes colocados à disposição dos novos empreendedores, como infraestrutura adequada e serviços compartilhados como laboratórios, telefone, Internet etc.

O movimento de incubação de empresas teve início nos Estados Unidos, referência mundial na cultura e disseminação do empreendedorismo, no final da década de 1930, quando Bill Hewlett e Dave Packard, dois jovens estudantes da Universidade de Stanford, próximo a Palo Alto, estado da Califórnia, iniciaram uma pequena empresa na garagem de casa com o incentivo de professores. O empreendimento viria a se tornar a Hewlett-Packard (HP), considerada uma das maiores e mais importantes empresas de equipamentos eletrônicos do mundo. Desde então, essa experiência serviu de modelo para o desenvolvimento de parques tecnológicos ao redor do mundo.

No Brasil, as primeiras incubadoras de empresas surgiram a partir de 1984, através de investimentos do CNPq na criação de cinco pólos tecnológicos em Campina Grande - Paraíba, Florianópolis - Santa Catarina, Manaus - Amazonas, Porto Alegre - Rio Grande do Sul e São Carlos - São Paulo. Em 1987 foi criada a Asso- ciação Brasileira de Entidades Promotoras de Empreendimentos Inovadores - ANPROTEC, que reunia as incubadoras de empresas existentes na época. Atualmente, dados da ANPROTEC apontam a existência de mais de 400 incubadoras em todo o País, que abrigam mais de 6.300 empresas, entre incubadas, graduadas e associadas.

No Estado do Ceará, assim como em outros estados brasileiros, as incubadoras estão reunidas em uma associação denominada Rede de Incubadoras do Ceará - RIC, que congrega, atualmente, nove incubadoras de empresas: o Parque de Desenvolvimento Tecnológico - PADETEC, vinculado à Universidade Federal do Ceará - UFC; a Incubadora do Instituto Centro de Ensino Tecnológico - CENTEC; a Incubadora do Núcleo de Tecnologia Industrial do Ceará - NUTEC; a Incubadora da Universidade Estadual do Ceará - INCUBAUECE; a Incubadora do Instituto da Tecnologia da Informação e Comunicação - ITIC; a Incubadora de Cooperativas Populares de Autogestão do Ceará, também da UFC; o Espaço de Desenvolvimento de Empresas de Tecnologia - EDETEC, vinculado à Universidade de Fortaleza - UNIFOR; o Programa de Incubação de Agronegócios - PROETA, ligado à Empresa Brasileira de Pesquisa Agropecuária - EMBRAPA; e a Incubadora do Instituto Federal de Ciência, Educação e Tecnologia do Ceará IFCE, objeto do estudo de caso para este trabalho.

A utilização de incubadoras de empresas como ferramentas indutoras do desenvolvimento e redução das disparidades intra-regionais tem propiciado, na última década, um considerável aumento da conscientização dos candidatos a empreendedores inovadores sobre a necessidade de buscarem ambientes propícios ao desenvolvimento. Por conta do crescimento do empreendedorismo no Brasil nas últimas duas décadas, e da necessidade cada vez maior das pessoas em abrirem seus próprios negócios, as universidades têm investido na criação de incubadoras de empresas e parques tecnológicos, de forma a atender uma demanda crescente de jovens empresários, na sua maioria estudantes de ensinos técnico ou superior, que desenvolvem projetos inovadores com a finalidade de transformá-los em oportunidades de negócios. Às incubadoras cabe a responsabilidade de oferecer toda a infra-estrutura e suporte para capacitar os aspirantes a empreendedores, preparando-os para se tornarem competitivos, inserindo-as nos mercados de forma independente e sustentável.

As discussões sobre o potencial dos processos de incubação como fatores propulsores da produção industrial levaram a Associação Brasileira de Entidades Promotoras de Empreendimentos Inovadores - ANPROTEC a buscar a formulação de um modelo ótimo 
A IMPORTÂNCIA DAS INCUBADORAS DE EMPRESAS PARA O DESENVOLVIMENTO ECONÔMICO SUSTENTÁVEL E REDUÇÃO DAS DISPARIDADES INTER-REGIONAIS: O CASO DA INCUBADORA DE EMPRESAS DO IFCE

para replicação entre suas entidades filiadas. Assim, estabeleceu-se o modelo denominado CERNE como padrão para as incubadoras brasileiras.

A adoção de um modelo para o processo de incubação não extingue, no entanto, particularidades relativas às interações locais, principalmente entre institutos de pesquisa e desenvolvimento e as dinâmicas empresariais. Esta constatação é benéfica para a contribuição das incubadoras para o desenvolvimento econômico local, pela necessidade de flexibilização dos processos às diferentes situações socioeconômicas.

O modelo de incubação adotado pelo Instituto de Educação, Ciência e Tecnologia do Estado do Ceará congrega as ações de complementação pedagógica, na medida em que promove o empreendedorismo inovador entre seus quadros de alunos e de egressos, e a inserção competitiva nos mercados locais, razão pela qual tornase objeto de estudo deste artigo, baseado em informações coletadas junto ao quadro gestor e às empresas incubadas, graduadas e associadas à Incubadora do Ifce.

\section{Empreendedorismo: a evolução do con- ceito}

Estudos relacionados ao desenvolvimento local têm colocado a ação empreendedora no centro da modificação de cenários econômicos de países e regiões, principalmente após a década de 1970. Naquele período, o conceito de empreendedorismo, que desde as afirmações do economista austríaco Joseph Schumpeter, no início do século XX, era restrito a seres "iluminados", que nasciam com talento especial para modificar ambientes econômicos pela introdução de novos produtos e serviços, começou a ser modificado para uma competência que pode ser desenvolvida e fortalecida para qualquer indivíduo.

A década de 1970 é também caracterizada pela popularização e interconexão de computadores, fato que fortaleceu o ressurgimento das pequenas e médias empresas no centro dos estudos econômicos. As grande plantas industriais não teriam mais condições de se adequarem às mudanças cada vez mais constantes nas demandas dos clientes, potencializada mais tarde com a Interne 11 Com o decorrer do tempo, as grandes indústrias modificaram seus processos industriais para se tornarem flexíveis e adaptativas, garantindo assim sua sustentação competitiva nos mercados.

Como conseqüência dos fatos acontecidos naquele período, não apenas no enfoque econômico (Nelson \& Winter; Freeman, Lundvall), mas também no aspecto

\footnotetext{
${ }^{1}$ Com o decorrer do tempo, as grandes indústrias modificaram seus processos industriais para se tornarem flexíveis e adaptativas, garantindo assim sua sustentação competitiva nos mercados.
}

da gestão empresarial ((DUCKER, 1987)), o Empreendedorismo vem-se consolidando como fundamental instrumento de desenvolvimento, devido ao dinamismo dos mercados que exige cada vez mais a de criação de pequenas empresas duradouras e a diminuição das altas taxas de mortalidade desses empreendimentos.

$\mathrm{O}$ termo Empreendedor tem origem no vocábulo francês entrepreneur, que significa uma pessoa que começa algo novo ou transforma um objeto existente, assumindo os riscos. Em outras palavras, o caráter empreendedor é atribuído a uma pessoa ou grupo de pessoas com capacidade de se dedicar a uma atividade, principalmente se ela for capaz de gerar riquezas, ou na transformação de conhecimentos e matéria-prima em produtos novos, mercadorias ou serviços em âmbito local, nacional ou mundial. A ação de empreender implica diversos objetivos. Zen e Fracasso (2008) apontam dois deles: o de angariar lucro, para uma ação individual, e o de reduzir as desigualdades sociais, no caso de uma ação coletiva.

Ducker (1987) ainda revela um elemento importante presente no empreendedorismo: a inovação, que, segundo ele, permite aos empreendedores detectarem uma oportunidade em um determinado negócio para que eles possam fazer algo diferente em um produto ou serviço, para que a inovação seja bem sucedida.

\section{As incubadoras de empresas}

Os empreendedores sempre estão em busca de grandes oportunidades para alavancarem seus negócios e obterem sucesso em seus empreendimentos. Porém, muitos deles, em especial os pequenos e médios empresários, donos de micro e pequenas empresas, sabem das possíveis dificuldades com que irão se deparar nessa trajetória e reconhecem que, sozinhos e sem nenhum auxílio de outros profissionais ou de entidades, as chances de fracasso tornar-se-ão cada vez maiores. Por isso, os empreendedores procuram estabelecer uma rede de contatos, buscando os melhores profissionais para assessorálos, além de orientações nos órgãos destinados a prestar consultorias empresariais.

Dentre os instrumentos de auxílio aos pequenos empresários destacam-se as incubadoras de empresas, que buscam incentivar o desenvolvimento de projetos inovadores, transformando-os em oportunidades de negócios, bem como capacitar os empreendedores e preparálos para mercados cada vez mais exigentes e competitivos. Define-se uma incubadora de empresas como um espaço institucional preparado para abrigar e apoiar potenciais projetos de pesquisa e transformá-los em micro e pequenas empresas desenvolvidas e lucrativas, propiciando aos novos empreendedores um espaço físico 
A IMPORTÂNCIA DAS INCUBADORAS DE EMPRESAS PARA O DESENVOLVIMENTO ECONÔMICO SUSTENTÁVEL E REDUÇÃO DAS DISPARIDADES INTER-REGIONAIS: O CASO DA INCUBADORA DE EMPRESAS DO IFCE

e compartilhado, dispondo de instrumentos essenciais para o aprimoramento de seus produtos e/ou serviços. Essas empresas, uma vez instaladas na incubadora recebem todo o tipo de capacitação e treinamento, tais como gestão empresarial, gestão tecnológica, comercialização de produtos e serviços nos mercados interno e externo, contabilidade, marketing, assistência jurídica, captação de recursos, contratos com financiadores, propriedade intelectual, entre outros. Geralmente as empresas permanecem na incubadora durante dois a três anos, tempo considerado suficiente para capacitação e preparação para o mercado.

Estimativas apontam que a taxa de mortalidade das micro e pequenas empresas amparadas por incubadoras é inferior em relação às empresas que nascem e crescem fora desse ambiente. De acordo com pesquisa realizada em 2011 pelo SEBRAE, 26,9\% das empresas deixam de existir nos dois primeiros anos de vida, considerado o período mais crítico para os empreendedores. Já para as empresas que crescem dentro de incubadoras, essa taxa de mortalidade cai para $20 \%$. Os principais motivos para o fechamento precoce das empresas são os problemas gerenciais, as dificuldades burocráticas, decorrentes de uma legislação ainda complexa e exigente aos pequenos empresários, além das elevadas taxas de juros sobre os empréstimos, culminando com a falta de acesso ao crédito.

\subsection{As primeiras incubadoras de empresas}

A primeira experiência de incubadora de empresas de que se tem notícia aconteceu no estado da Califórnia, na região conhecida atualmente como Vale do Silício, famosa mundialmente por ser o berço das mais importantes e inovadoras empresas que, nos últimos anos, promoveram grandes mudanças tecnológicas e que tornaram inovações com alta agregação de tecnologia cada vez mais próximas do cotidiano das pessoas, tais como a Apple, Google, Microsoft, entre outras. O êxito promovido pela Universidade de Stanford, em 1937, ao dar apoio a dois estudantes recém-graduados, Bill Hewlett e David Packard, para abrir uma empresa, enfocando a fabricação de um inovador equipamento eletrônico, é o principal exemplo recente do potencial indutor dos processos de inovação. Os estudantes foram agraciados com bolsas e tiveram acesso ao laboratório de radiocomunicações da Universidade. Essa iniciativa deu origem à empresa Hewlett-Packard, conhecida também pela sigla HP, que hoje é uma das maiores empresas de hardware e software do mundo. O sucesso alcançado pela Universidade na criação da HP culminou na implantação de um Parque Industrial, e mais tarde, de um Parque Tecnológico na Região, o Standford Research
Park, que estimulou a reprodução de iniciativas semelhantes em outras localidades do mundo.

No continente europeu, foi na Inglaterra, país onde se iniciou a Primeira Revolução Industrial, no século XVIII, que surgiram as primeiras incubadoras de empresas, decorrentes do fechamento de uma subsidiária da British Steel Company, fato que, segundo Morais (1997, p. 42-43, apud MCT, 2000, p. 10), estimulou a criação de pequenas empresas em áreas relacionadas com a produção de aço, preconizando um processo de terceirização, e também em decorrência do reaproveitamento de prédios subutilizados.

\subsection{As incubadoras de empresas no Brasil}

No Brasil, a implantação do ParqTec - Fundação Parque de Alta Tecnologia da cidade de São Carlos, no interior de São Paulo, uma iniciativa do CNPq, em dezembro de 1984, marcou o início da trajetória da primeira incubadora de empresas, não apenas no Brasil, mas em toda a América Latina. Logo depois, cidades como Joinvile/SC, Campina Grande/PB, Manaus/AM e Santa Maria/RS também implantaram incubadoras em suas respectivas regiões, com o objetivo de se criarem empreendimentos de base tecnológica em cada um desses lugares.

Em 1987, o surgimento da Associação Nacional de Entidades Promotoras de Empreendimentos de Tecnologia Avançada - ANPROTEC, entidade que reunia as incubadoras existentes até então, iniciou uma articulação do movimento de criação e expansão das incubadoras de empresas de base tecnológica, além do surgimento de parques e pólos tecnológicos em diversas localidades do País. A partir daí, o número de incubadoras em todo o Brasil não parou de crescer. Vinte e quatro anos depois, em 2011, dados da ANPROTEC contabilizavam em todo o Brasil cerca de 400 incubadoras, que juntas apoiaram mais de 6.300 empresas e geraram 33 mil empregos diretos.

No Estado do Ceará, a primeira incubadora de empresas a ser implantada foi o Parque de Desenvolvimento Tecnológico - PADETEC, vinculado à Universidade Federal do Ceará. A sua criação deu-se em 1990 e a inauguração aconteceu, segundo o site da referida instituição, aconteceu em 5 de junho de 1991. Inicialmente o PADETEC era destinado à criação de empresas de base tecnológica e, desde o início auxiliou o desenvolvimento de pesquisas nas mais variadas áreas, como química fina, eletrônica, mecânica, alimentos e suplementos alimentares, cosmética, compostos, fitoterápicos, produtos naturais, energia alternativa, dentre outros.

Além do PADETEC, atualmente, o Ceará conta com 
A IMPORTÂNCIA DAS INCUBADORAS DE EMPRESAS PARA O DESENVOLVIMENTO ECONÔMICO SUSTENTÁVEL E REDUÇÃO DAS DISPARIDADES INTER-REGIONAIS: O CASO DA INCUBADORA DE EMPRESAS DO IFCE

outras incubadoras de empresas, quase todas ligadas a uma universidade ou instituição de ensino: a Incubadora do Instituto Centro de Ensino Tecnológico - CENTEC; a Incubadora do Núcleo de Tecnologia Industrial do Ceará - NUTEC; a Incubadora da Universidade Estadual do Ceará - INCUBAUECE; a Incubadora do Instituto da Tecnologia da Informação e Comunicação ITIC; a Incubadora de Cooperativas Populares de Autogestão do Ceará, que assim como o PADETEC, também está localizada no campus da UFC; o Espaço de Desenvolvimento de Empresas de Tecnologia - EDETEC, vinculado à Universidade de Fortaleza - UNIFOR; o Programa de Incubação de Agronegócios - PROETA, ligado à Empresa Brasileira de Pesquisa Agropecuária EMBRAPA; e a Incubadora do Instituto Federal de Ciência, Educação e Tecnologia do Ceará - IFCE. Todas elas fazem parte de uma associação denominada Rede de Incubadoras do Ceará - RIC, criada em 2002 e que tem como missão ser uma instituição facilitadora do fortalecimento do empreendedorismo inovador no Estado.

\section{A incubadora de empresas do IFCE}

A Incubadora de Empresas do Instituto Federal de Educação, Ciência e Tecnologia do Ceará - IE-IFCE, é uma das incubadoras pertencentes à Rede de Incubadoras de Empresas do Ceará - RIC. No site da instituição ela é definida como:

uma ação pedagógica que oferece suporte aos alunos e egressos dos diversos cursos regulares, para desenvolverem suas ideias e transformá-las em oportunidades de geração de negócios inovadores, que atendam ou induzam demandas do mercado. (IFCE, 2015).

Percebe-se, através desta definição, que a Incubadora mantém a característica fundamental das afiliadas da ANPROTEC, que é a criação e a consolidação de projetos e a sua transformação em produtos ou serviços inovadores, através do apoio e suporte às empresas incubadas, como consultorias especializadas, orientação técnica, laboratórios e infra-estrutura compartilhada, com acessos a fax, telefone, internet, e um espaço reservado à realização de reuniões.

O diferencial desta incubadora é o seu público-alvo específico: alunos e ex-alunos da Instituição, por sua característica de ferramenta de complementação pedagógica, pelo incentivo que proporciona a alunos e egressos na construção de negócios inovadores sustentáveis, e da prática empreendedora nas áreas compatíveis com as atividades de ensino, pesquisa e extensão no Campus Fortaleza do IFCE.
O início das atividades da IE-IFCE data do ano de 1996, quando a instituição ainda se chamava Escola Técnica Federal do Ceará - ETFCE, com a criação de um Núcleo de Inovação Tecnológica - NIT, cujo anteprojeto, concluído no ano seguinte, previa a criação de uma incubadora de empresas na referida instituição de ensino e a capacitação de docentes para a implantação e consolidação da prática do empreendedorismo no local. Mais tarde, apareceram os primeiros parceiros, como o Serviço de Apoio às Micro e Pequenas Empresas - SEBRAE e o Banco do Nordeste - BNB, que financiou a construção de dois ambientes para a instalação da Incubadora, além de um balcão tecnológico.

A Incubadora de Empresas, propriamente dita, com espaço próprio, foi inaugurada no ano de 2004 e a sua modalidade de incubação é de caráter misto, abrigando empresas tanto de base tecnológica, como dos setores tradicionais da economia, como produtos e serviços, funcionando como um agente facilitador na geração, desenvolvimento e consolidação de empreendimentos inovadores e preparando-os para o mercado de trabalho. A entrada de novos projetos de empresas ocorre por meio de editais. Desde a sua criação até 2012, dezoito projetos passaram pela Incubadora. Atualmente, cinco empresas participam ativamente do processo de incubação

Atualmente, a Incubadora ocupa duas áreas dentro do IFCE, seu parceiro mantenedor que, juntas, totalizam uma área de aproximadamente $90 \mathrm{~m}^{2}$, sendo que um desses espaços é um ambiente arquitetado com paredes de vidro, inaugurado no ano de 2008, com o objetivo de ampliar a capacidade de abrigar novas empresas. Está localizado em uma área de grande movimentação de estudantes, professores e servidores. As figuras a seguir mostram a infra-estrutura da Incubadora de Empresas do IFCE.

Além do BNB e do SEBRAE, hoje a Incubadora conta também com o apoio do Governo do Estado do Ceará, através da Secretaria de Ciência e Tecnologia - SECITECE - e da Fundação Cearense de Apoio ao Desenvolvimento Científico e Tecnológico - FUNCAP, além de órgãos federais ligados à tecnologia e pesquisa científica, como o Conselho Nacional de Desenvolvimento Científico e Tecnológico - CNPq - e a Financiadora de Estudos e Projetos do Ministério da Ciência e Tecnologia - FINEP. Também é importante ressaltar o apoio que recebe das outras incubadoras e parques tecnológicos membros da RIC.

\section{O processo de coleta e análise dos dados}

Para a realização do estudo de caso, foram elaborados dois roteiros de entrevistas, de caráter estruturado e de 
Figura 1: Fotos ilustrativas da Incubadora do IFCE

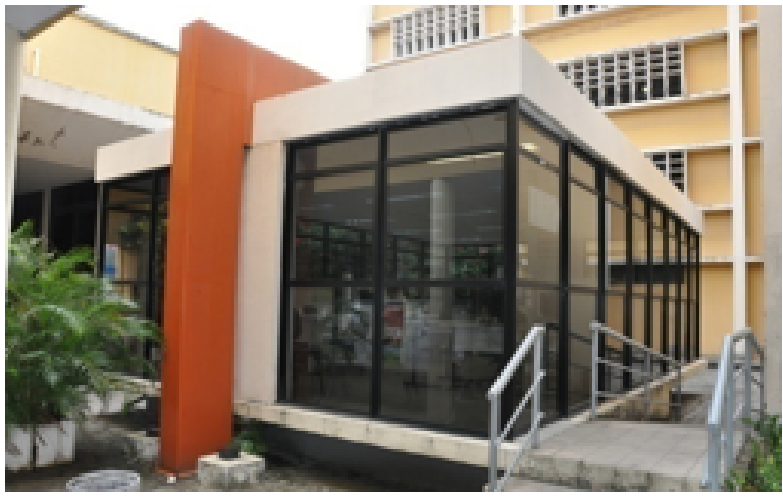

A - Estrutura externa da Incubadora

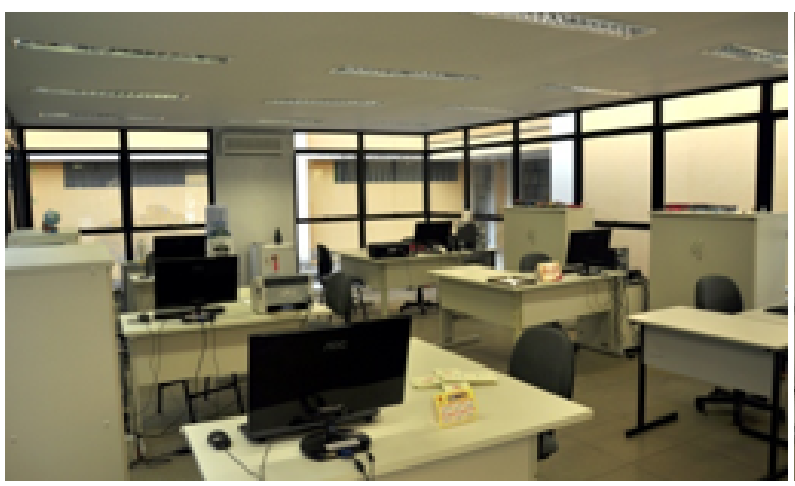

C - Estrutura interna da Incubadora

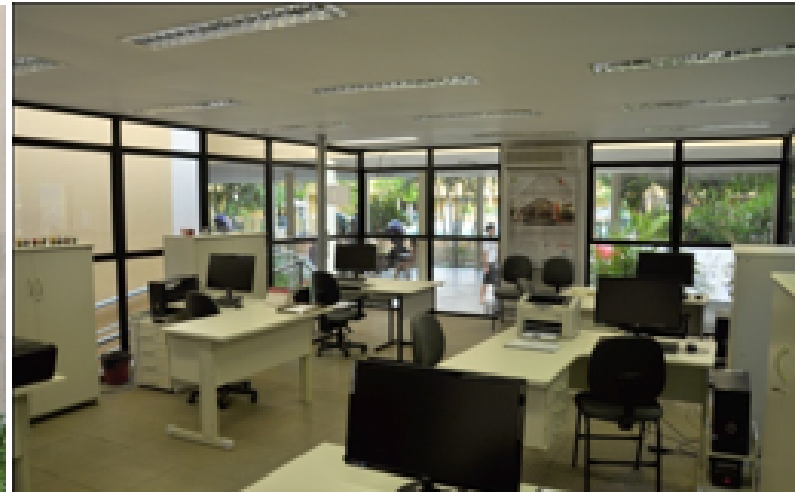

B - Estrutura interna da Incubadora

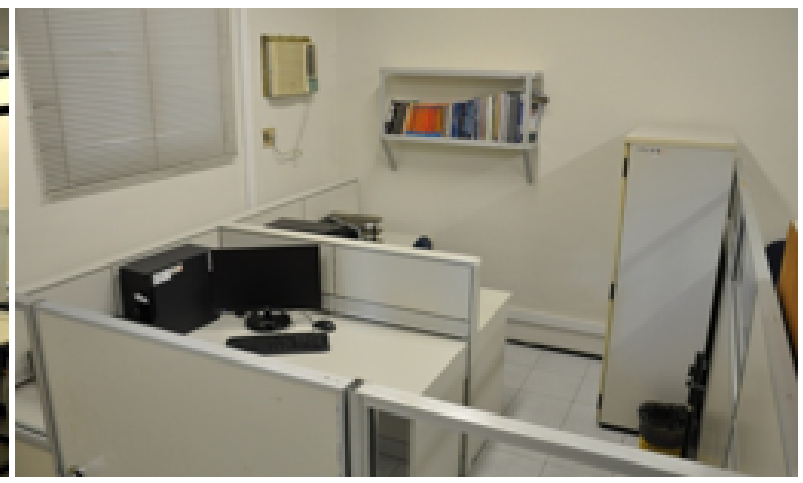

D - Estrutura interna da Incubadora

Fonte: FREITAS (2012) 
A IMPORTÂNCIA DAS INCUBADORAS DE EMPRESAS PARA O DESENVOLVIMENTO ECONÔMICO SUSTENTÁVEL E REDUÇÃO DAS DISPARIDADES INTER-REGIONAIS: O CASO DA INCUBADORA DE EMPRESAS DO IFCE

natureza qualitativa, que se encontram apresentados nos apêndices: o primeiro, com uma pequena quantidade de questões abertas, destinou-se às pessoas que fazem parte da equipe de membros da incubadora (coordenação, bolsistas, servidores, etc.), que opinaram sobre o papel que a Incubadora do IFCE exerce no processo de desenvolvimento da ação empreendedora, além de identificarem as qualidades e competências essenciais para que um candidato a empreendedor possa ingressar na Incubadora.

O segundo roteiro foi elaborado especialmente para os empresários responsáveis pelas empresas que participam do Programa de Incubação de Empresas do IFCE e que fazem parte do público-alvo da Incubadora. Esse roteiro possuiu uma quantidade bem maior de perguntas em relação ao primeiro, com perguntas abertas e objetivas, com respostas previamente estabelecidas, o suficiente para que os entrevistados abordassem amplamente o processo de incubação. Dentre os questionamentos efetuados, destacam-se a experiência de empreendedor, os motivos que levaram à criação das referidas empresas e sobre o quanto a Incubadora de Empresas do IFCE tem contribuído para o desenvolvimento de seus empreendimentos.

A partir das respostas oferecidas pelos entrevistados, procurou-se agrupá-las por semelhanças, tendo em vista a utilização de perguntas abertas, sem entretanto, perder a essência do sentimento do entrevistado.

Quanto aos fatores significativos da relação entre a Incubadora e o estímulo ao Empreendedorismo como fator de desenvolvimento local, os entrevistados mencionaram a geração de ambientes inovadores e estruturados, dando o suporte gerencial necessário para que os alunos e futuros empresários desenvolvam as suas idéias, transformando-as em oportunidades de negócios, através do apoio gerencial, de um espaço inicial para o desenvolvimento mútuo das ações empresariais e laboratoriais, disponibilizados aos mesmos, além da oferta de consultorias, do network e, até mesmo da participação das empresas incubadas em eventos e em cursos de capacitação oferecidos aos empreendedores.

As respostas conferidas pelos entrevistados levaram à conclusão de que há, entre eles, um alto grau de reconhecimento da importância do trabalho que cada um exerce na Incubadora de Empresas do IFCE, no tocante às ações de incentivo à capacitação dos empresários e ao desenvolvimento das empresas participantes. Por essas razões a incubadora tornou-se referência maior na prática da ação empreendedora dentro do IFCE.

A segunda etapa do processo de investigação constou de questionários respondidos pelos empresários participantes do programa de incubação, com o objetivo de conhecer o perfil desses empreendedores, além dos facultar-lhes a oportunidade de emitir opiniões a respeito das experiências que acumularam ao longo do período de incubação de suas empresas e sobre o quanto a Incubadora do IFCE tem contribuído para o crescimento e desenvolvimento desses empreendimentos. Os empresários escolhidos participavam, na época da pesquisa, do Programa de Incubação nas categorias de préincubação; incubação residente e não residente; e pósincubada ou associada.

Sobre a ação da incubadora como instrumento de complementação pedagógica, e específicamente seu impacto sobre o corpo discente do Instituto, percebeuse que, dos sete empreendedores entrevistados, quatro eram ex-alunos e três ainda estavam vinculados à Instituição, sendo dois matriculados em cursos de pós graduação e um em curso de graduação. É interessante ressaltar a importância, percebida nas entrevistas, da pós graduação universitária como alicerce para as atividades empresariais.

Dentre as empresas incubadas sobressaem-se atividades ligadas às Tecnologias da Informação e das Comunicações, provavelmente pela vertente empreendedora que se percebe em alunos dessas áreas. Espera-se que no futuro a infra-estrutura laboratorial de que dispõe o Instituto possa prestar suporte a outras atividades empreendedoras.

As empresas vinculadas à Incubadora de Empresas que responderam ao questionário são assim descritas:

- empresa que atua na área de tecnologia embarcada;

- agência especializada em comunicação e marketing digital, cujos principais serviços são o desenvolvimento de sites personalizados e a divulgação do mesmo na Internet;

- empresa que desenvolve um software na área de logística;

- empreendimento voltado para serviços e soluções na área de planejamento de trânsito e transportes para cidades e empreendimentos;

- empresa de educação voltada para a questão do meio ambiente, especificamente a educação ambiental, que se utiliza de interações lúdicas como forma de facilitação do aprendizado.

De acordo com as informações coletadas nos questionários, sobre o tempo de incubação das empresas que participaram da pesquisa, todas informaram participar há, pelo menos, um ano no programa de incubação de empresas, sendo que duas empresas já participam do program de incubação há 1 ou 2 anos;, outras duas empresas estão incubadas no período entre 2 e 3 anos; duas outras, entre 3 e 4 anos; e apenas uma) em- 
A IMPORTÂNCIA DAS INCUBADORAS DE EMPRESAS PARA O DESENVOLVIMENTO ECONÔMICO SUSTENTÁVEL E REDUÇÃO DAS DISPARIDADES INTER-REGIONAIS: O CASO DA INCUBADORA DE EMPRESAS DO IFCE

presa participa do programa de incubação há mais de 4 anos. Ressalta-se, ainda, que a única empresa que está na Incubadora há mais de quatro anos já está graduada, encontrando-se, por isso, na condição de associada ou pós-incubada. Em outras palavras, o empreendimento em questão é considerado um caso de sucesso bem sucedido dentro da Incubadora do IFCE.

Com relação às expectativas que cada empreendedor tinha ao ingressar na Incubadora do IFCE, é quase unânime o desejo de ver a empresa crescer, permanecer e se consolidar no mercado em que atua, transformando-se em referência na atividade, graças ao apoio que a Incubadora oferece ao desenvolvimento de novas idéias e ao estabelecimento de novas parcerias.

$\mathrm{Na}$ opinião dos entrevistados, depois de um certo período na incubadora, a maioria se mostra satisfeita com os resultados alcançados em cada empreendimento.Um deles destaca que as condições de infraestrutura da incubadora foram essenciais para a projeção da sua empresa no mercado.Outro entrevistado destaca que o aprendizado foi um fator importante, tanto na parte técnica, quanto em relação ao mercado no qual a empresa atua. O mesmo menciona ainda que o seu empreendimento, com menos de dois anos de formalização e menos de quatro de atuação, já é referência no Estado do Ceará no mercado onde a empresa está inserida.

Dentre os entrevistados, quando questionados sobre as razões que os levaram a criar suas empresas, três apontaram a vontade de poder atuar no ramo pelo qual a empresa está inserida no mercado; dois ressaltaram o acesso a informações acerca do mercado em que as empresas atuam; e dois destacaram o fato de que o seu empreendimento atua em um mercado pouco explorado.

Quanto à maneira com que ficaram sabendo da Incubadora de Empresas do IFCE, as respostas foram bastante divididas. Para dois dos empreendedores entrevistados, foi através da própria Incubadora do IFCE que receberam as informações acerca de como ter a sua empresa incubada, dos editais de seleção e do processo de incubação. Outros dois entrevistados responderam que foi através dos professores, de seus respectivos cursos, que receberam incentivos e motivação para procurar a Incubadora do IFCE. Cada uma das outras respostas sugeridas no questionário (em jornais ou revistas da instituição, na Internet e através de colegas do IFCE) foi ressaltada por um único entrevistado.

Sobre os serviços oferecidos pela Incubadora de Empresas do IFCE, é importante ressaltar que o instrumento de coleta permitia, para esse tema, a escolha de mais de uma opção. De acordo com os dados coletados entre os empreendedores pesquisados, os serviços mais mencionados foram as consultorias (jurídicas, contá- beis, financeiras, entre outras), citados por seis empreendedores, além da própria infra-estrutura da incubadora, e a oportunidade de participar de eventos e feiras, em que tiveram a chance de apresentar a empresa e os produtos ou serviços que produzem. Esses dois últimos serviços receberam menção de cinco entrevistados cada. Os treinamentos e os cursos ofertados pelos parceiros da Incubadora também foram citados, porém em menor escala. Além disso, um dos entrevistados destacou o network entre parceiros como um dos serviços que ele e o seu empreendimento receberam durante o período de incubação.

Assim como os membros da equipe da Incubadora do IFCE, os responsáveis pelas empresas também opinaram sobre a definição do que é ser um empreendedor. Procurou-se agrupar as respostas oferecidas pelos entrevistados por semelhanças, tendo em vista a utilização de perguntas abertas, sem, entretanto, perder a essência do sentimento do entrevistado. Ressalta-se ainda que, mesmo sendo uma questão aberta, todos os empreendedores entrevistados responderam a essa pergunta.

De acordo com a opinião dos entrevistados, os empreendedores são pessoas diferenciadas dos trabalhadores convencionais, por serem desbravadores de novas idéias, que vêem oportunidades em locais ou situações que normalmente não foram percebidas, ou que ainda não existem. Assim procuram transformar o conhecimento adquirido, seja nas instituições de ensino, ou naturalmente, na percepção das atividades do cotidiano, em um negócio de sucesso que valorize suas idéias, e que seja útil à humanidade e que possa garantir sua independência financeira.

Ainda de acordo com a visão dos entrevistados, os empreendedores são pessoas que têm sonhos e reúnem esforços para concretizar um empreendimento. São trabalhadores motivados para realizar as atividades, sabem aprender com os erros e perseveram para continuar a sua caminhada em busca de melhorias para a empresa que administram.

Foi também pedido aos empreendedores que cada um mencionasse três características ou qualidades que eles adquiriram durante a experiência na Incubadora do IFCE e que contribuiu para o crescimento dos respectivos empreendimentos. Foi outro item da pesquisa respondido por seis entrevistados. A seguir, têm-se as respostas mais mencionadas pelos entrevistados:

- Amadurecimento, busca de oportunidades e maior conhecimento da área escolhida;

- Maturidade, pessoal e poder de persuasão;

- Organização, formação de preço e marketing de uma forma geral;

- Criatividade, perseverança e disposição; 
A IMPORTÂNCIA DAS INCUBADORAS DE EMPRESAS PARA O DESENVOLVIMENTO ECONÔMICO SUSTENTÁVEL E REDUÇÃO DAS DISPARIDADES INTER-REGIONAIS: O CASO DA INCUBADORA DE EMPRESAS DO IFCE

$$
\text { cia; }
$$

- Autoconfiança, busca de informações e persistên-

- Conhecimento, paciência e persistência.

Dessas características levantadas, pediu-se a cada um dos entrevistados que elegesse uma delas como a mais importante, justificando sua escolha. Para dois dos entrevistados, o amadurecimento ou maturidade foi considerado como mais relevante para o sucesso das suas empresas. Um outro enfatizou a questão do aprendizado, pois, segundo esse empreendedor, o aprendizado com os erros é bem maior do que com os acertos. Um outro ressaltou a idéia de que, além da maturidade, é necessário ter paciência para continuar focado no projeto, pois, mais cedo ou mais tarde, vai se concretizar.

Analisando essas duas respostas, percebe-se comungam o fator "persistência"como um importante aliado para se alcançar um objetivo ao empreendimento.

O terceiro entrevistado escolheu como característica mais importante a formação de preço, pois para ele é fundamental saber, em cada caso, estabelecer um preço justo e lucrativo ao negócio, sendo fundamental para a sobrevivência de uma empresa.

O quarto empreendedor escolheu a criatividade, pois, segundo o mesmo, com ela, pode se adaptar às diversidades do mercado, aprender a trabalhar e atender às necessidades de cada cliente.

A busca de informações foi apontada pelo quinto empreendedor entrevistado, porque, na opinião dele, sem elas não dá para planejar como vai atingir os objetivos traçados.

O sexto e último empreendedor escolheu como mais importante o conhecimento, pois, na sua visão, durante o processo de incubação da sua empresa, o acúmulo de informações e habilidades que fizeram o projeto foi responsável direto pela evolução do projeto.

Para encerrar a pesquisa, cada empreendedor entrevistado foi solicitado a, em uma escala de 0 a 10, definir o grau de importância que uma incubadora de empresas tem no estímulo à prática empreendedora. A escala de importância, adotada para essa avaliação, teve a seguinte variação: de 0 a 2, a incubadora de empresas tem importância no estímulo à prática empreendedora; de 2 a 4, ela tem alguma importância, mas de forma insignificante para o empreendedorismo; de 4 a 6 , a incubadora tem importância mediana; de 6 a 8, a incubadora tem importância um pouco maior; por fim de 8 a 10 , a incubadora de empresas tem importância vital para o estímulo à prática empreendedora.

Segundo as avaliações realizadas por todos entrevistados onde, através de uma média simples, somando todas as notas obtidas e dividindo o resultado pelo número de entrevistados, obteve-se a nota 8,86. Pode-se con- cluir, pelo resultado auferido, que na visão dos empreendedores, a incubadora de empresas tem uma importância excepcional para o desenvolvimento das ações empreendedoras.

\section{Considerações finais e sugestões para tra- balhos futuros}

A partir da análise das informações coletadas, e à luz do referencial teórico pertinente, o estudo de caso realizado na Incubadora de Empresas do Instituto Federal de Educação, Ciência e Tecnologia do Ceará - IFCE levou à conclusão de que as incubadoras de empresas, de fato, contribuem significativamente para o desenvolvimento do Empreendedorismo. Os resultados da pesquisa ratificam aqueles obtidos pelo SEBRAE em 2011, que comprovaram que a taxa de mortalidade das empresas incubadas é menor do que das micro e pequenas empresas em geral.

Quanto ao papel que uma incubadora de empresas exerce como ferramenta de estímulo e consolidação do empreendedorismo, na Incubadora do IFCE, em particular, destacam-se o suporte técnico às empresas nascentes e o desenvolvimento de atividades de forma proativa no tocante a sua missão de complementação da ação pedagógica do Instituto que abriga a Incubadora. A Incubadora apresenta alguns casos de sucesso de empreendimentos que estão ou que já passaram pela mesma, dentre os quais, pode-se destacar o trabalho de uma empresa, cuja atividade é destinada ao desenvolvimento de sites personalizados, cujo responsável declarou que, mesmo sendo uma empresa incubada, tornouse referência no Ceará no mercado onde a empresa está inserida e que, portanto, teve o seu trabalho reconhecido pelo segmento em que atua.

Dentre as influências sócio-econômicas que as incubadoras de empresas exercem no desenvolvimento das empresas incubadas, podem-se identificar, na pesquisa realizada, algumas características relevantes, como os efeitos da ação pedagógica da Incubadora no desenvolvimento sustentável do Estado, além do auxílio ao conhecimento e acesso a instrumentos financeiros disponíveis por órgãos de desenvolvimento, como BNB, FINEP e SEBRAE, destinados tanto à própria Incubadora quanto às empresas incubadas.

Os depoimentos colhidos entre os empreendedores entrevistados levou à constatação de que a identificação com a atividade e o mercado consumidor é o motivo mais relevante para o desenvolvimento de um novo empreendimento. Além do mais, os entrevistados destacaram o desejo de ver as suas empresas crescerem e se consolidarem. Verificou-se também que a maioria dos empreendedores que já se encontram em estágios mais 
A IMPORTÂNCIA DAS INCUBADORAS DE EMPRESAS PARA O DESENVOLVIMENTO ECONÔMICO SUSTENTÁVEL E REDUÇÃO DAS DISPARIDADES INTER-REGIONAIS: O CASO DA INCUBADORA DE EMPRESAS DO IFCE

avançados de incubação ou já graduados se mostra satisfeita com os resultados obtidos em seus empreendimentos.

Por fim, dentre os valores extraídos do trabalho que o processo de incubação de empresas exerce no estímulo ao Empreendedorismo, em especial, na Incubadora de Empresas do IFCE, merece relevo a importância conferida ao aprendizado, tanto por parte das pessoas que trabalham em prol do desenvolvimento e consolidação das empresas, quanto para os empreendedores responsáveis pelas mesmas.

Em resumo, o estudo realizado possibilitou, além da confirmação dos efeitos positivos do processo de incubação no desenvolvimento sustentável de países e regiões, a percepção de que o modelo de incubação adotado no Instituto Federal fortalece a conexão entre as atividades acadêmica e empresarial, na medida em que prioriza o apoio e monitoração da trajetória tecnológica e negocial de empreendimentos oriundos do corpo discente da instituição que a abriga. Sugere-se, por isso, o aprofundamento nos esforços de aperfeiçoamento e replicação da metodologia de complementação pedagógica e interação negocial adotada na Incubadora de Empresas localizada no Campus Benfica do Instituto Federal de Educação, Ciência e Tecnologia do Ceará, não apenas entre outros institutos federais, mas em toda instituição de pesquisa que busque fortalecer a conexão entre os projetos acadêmicos e o tecido empresarial.

Sugere-se, para trabalhos futuros, a análise da possibilidade de replicação do modelo adotado na Incubadora de Empresas do IFCE para outros campi da Instituição. Sugere-se também estudar a visão dos alunos do Instituto, principalmente aqueles que tenham cursado disciplinas voltadas ao Empreendorismo, sobre a ação da Incubadora como complemento da ação pedagógica.

\section{REFERÊNCIAS}

AGÊNCIA BRASIL. Brasil Empreendedor: cerca de R\$ 3,8 milhões aplicados no Nordeste. Brasília: Agência Brasil, 2002. Disponível em: <http://agenciabrasil.ebc.com.br/node>. Acesso em: 23 fev. 2012.

Cadastro de empreendedores individuais tem 1,8 milhão de registros em 2011. Brasília: Agência Brasil, 2012. Disponível em: <http://migre.me/ulR5P> Acesso em: 23 fev. 2012.

BIZZOTO, C. E. N. O que é uma incubadora de empresas. Blumenau: Diretiva, 2008.

Conex. Ci. e Tecnol. Fortaleza/CE, v. 10, n. 3, p. 7 - 19, nov. 2016
DALTRO, A. L.; OYAMA, E. As lições dos vencedores. Veja, edição 2245, ano 44, n. 48, p. 122-130, 30 nov. 2011.

DOLABELA, F. O segredo de Luísa. 30. ed. São Paulo: Editora de Cultura, 2006.

DORNELAS, J. C. A. Empreendedorismo: transformando idéias em negócio. Rio de Janeiro: Campus, 2001.

Planejando incubadoras de empresas: como desenvolver um plano de negócios para incubadoras. Rio de Janeiro: Campus, 2002.

DUCKER, P. F. Inovação e espirito empreendedor: prática e principios. 2. ed. São Paulo: Pioneira, 1987. Tradução de Carlos Malferrari.

GIL, A. C. Métodos e técnicas de pesquisa social. 4. ed. São Paulo: Atlas, 1994.

GRECO, S. M. d. S. S. Empreendedorismo no Brasil: 2010. Curitiba: IBQP, 2010.

SALOMÃO, J. R. As incubadoras de empresas pelos seus gerentes: uma coletânea de artigos. Brasília: Associação Nacional de Entidades Promotoras de Empreendimentos de Tecnologias Avançadas (ANPROTEC), 1998.

SANTOS, S. A. Empreendedorismo de base tecnológica: evolução e trajetória. Maringá-PR: Unicorpore, 2005.

SEBRAE. Incubadora de empresas: apoio completo para o seu projeto. Disponível em: <http://www.sebrae.com.br/customizado/inovacao/ acoes-sebrae/incubadora-de-empresas $>$. Acesso em: 22 out. 2011

ZEN, A. C.; FRACASSO, E. M. Quem é o empreendedor? As implicações de três revoluções tecnológicas na construção do termo empreendedor. 2008. Disponível em: <http://www3.mackenzie.br/editora/index.php> Acesso em: 29 mai. 2012. 
A IMPORTÂNCIA DAS INCUBADORAS DE EMPRESAS PARA O DESENVOLVIMENTO ECONÔMICO SUSTENTÁVEL E REDUÇÃO DAS DISPARIDADES INTER-REGIONAIS: O CASO DA INCUBADORA DE EMPRESAS DO IFCE

APÊNDICE A - ROTEIRO DA ENTREVISTA FORMULADA AOS INTEGRANTES DA INCUBADORA DO IFCE

- Na sua opinião, qual o papel desempenhado pela Incubadora de Empresas do IFCE no processo de desenvolvimento da ação empreendedora?

- Na sua opinião, quais os fatores significativos da relação entre a Incubadora de Empresas do IFCE no estímulo às práticas empreendedoras?

- Cite, na sua opinião, três características mais importantes para uma pessoa tornar-se empreendedor de uma empresa incubada na Incubadora de Empresas do IFCE?

- Dessas três, qual, na sua opinião, é a mais importante? Por quê? 


\section{APÊNDICE B - ROTEIRO DA ENTREVISTA FORMULADA AOS EMPRESÁRIOS DA INCUBADORA DE EMPRESAS DO IFCE:}

\section{Idade do empresário}
a. ( ) entre 18 e 24 anos
b. ( ) entre 25 e 30 anos
c. ( ) entre 31 e 35 anos
d. ( ) entre 36 e 40 anos
e. ( ) acima de 40 anos

2. Qual a formação educacional atual do empresário?
a. ( ) ensino médio completo
b. ( ) ensino técnico incompleto
c. ( ) ensino técnico completo
d. ( ) ensino superior incompleto
e. ( ) ensino superior completo
f. ( ) pós-graduação

3. Defina, nas suas palavras, o ramo de seu empreendimento?

4. Na época do seu ingresso e de sua empresa na Incubadora, qual a sua condição em relação ao IFCE?
( ) aluno
( ) ex-aluno

5. Há quanto tempo a sua empresa participa do programa de incubação de Empresas do IFCE?
( ) menos de 1 ano
( ) entre 1 e 2 anos
( ) entre 2 e 3 anos
( ) entre 3 e 4 anos
( ) mais de 4 anos

6. O que mais lhe motivou na criação da sua empresa? (marque apenas uma opção)
( ) conhecimento do mercado em que atua
( ) vocação para empreender
( ) atuar em um ramo pouco explorado
( ) gosto pela área escolhida
( ) outros motivos 
7. De que maneira você ficou sabendo da Incubadora de Empresas do IFCE?
a. ( ) através de colegas do IFCE
b. ( ) através de professores do IFCE
c. ( ) na própria Incubadora de Empresas
d. ( ) jornais ou revistas da instituição
e. ( ) na Internet
f. ( ) outro

8. Qual era a sua expectativa com relação à sua empresa e a sua carreira de empreendedor na época em que entrou na Incubadora de Empresas do IFCE?

9. Quais os mais importantes serviços e consultorias que seu empreendimento recebeu durante o período de incubação? (marque uma ou mais opções)
a. ( ) consultorias (contábeis, jurídicas, marketing, financeiras, etc.)
b. ( ) treinamentos
c. ( ) participação em eventos
d. ( ) cursos ofertados pelos parceiros da Incubadora (SEBRAE, BNB, etc.)
e. ( ) infra-estrutura (limpeza, segurança, fax, telefone, internet, etc.)
f. ( ) outros

10. Você acredita que as expectativas iniciais foram atendidas parcialmente, totalmente ou foram além das suas expectativas com relação ao desenvolvimento e crescimento de sua empresa e de sua carreira de empreendedor? Por quê?

11.Defina, na sua opinião, o que é ser um empreendedor?]

12. Cite três características (qualidades) de empreendedor que você adquiriu e que the ajudou no processo de desenvolvimento $e$ crescimento de sua empresa?

13. Dessas três, para você, qual é a mais importante? E por quê?

14. Uma nota de 0 a 10: Qual o grau de importância de uma incubadora de empresas no estímulo à prática empreendedora?

\begin{tabular}{|l|l|l|l|l|l|l|l|l|l|l|}
\hline 0 & 1 & 2 & 3 & 4 & 5 & 6 & 7 & 8 & 9 & 10 \\
\hline & & & & & & & & & & \\
\hline
\end{tabular}

